\title{
A Case Study on Sexually Harass Women in a Crime Spot
}

\author{
Basu N and Bandyopadhyay SK* \\ Department of Computer Science \& Engineering, \\ University of Calcutta, India \\ *Corresponding author: Samir Kumar \\ Bandyopadhyay, Department of Computer Science \& \\ Engineering, University of Calcutta, India
}

Received: May 23, 2017; Accepted: J une 27, 2017;

Published: July 12, 2017

\begin{abstract}
Killing of a human being is a serious crime. Bloodstain Pattern Analysis (BPA) interprets the shape and distribution of bloodstains in a crime scene. Murderers conceal crime so that it may be wrong interpretation by autopsy surgeons and hence it may lead to injustice. The mentality of murderer after crime is to hide the crime by disposing of the dead bodies by burning, burying, throwing them into water or concealing them in distant places. This paper presents a case on Sexually Harassment of Women in an Incidence. In this case none of persons i.e. victims, suspects and experts involved providing their advice are going to be named, because the basic aim of this paper is to explain the incidence happened at the crime. Further in the content of case diary names of victims are not mentioned.
\end{abstract}

Keywords: Crime scene; Visit; Forensic expert; Accident; Assault

\section{Introduction}

Crime Reconstruction of the consecutive events from autopsy and visit at crime spot is essential for investigations. The presence of blood patterns at the crime scene is importance for the investigation. The distribution of blood patterns can provide vital information on the chain of events caused at crime scene. Proper interpretation of blood patterns by the expert must have built up knowledge of and experience in the types of stains and distributions, which may be caused by various forms of injuries and mechanisms.

Crime Scene visiting is necessary for understanding in some of the mysterious cases for Identifying dead person, time since death \& cause of Death. The function of BPA at the scene of death is generally to assess the environment, the local circumstances and the position of the body in relation to the nearby objects, the condition of the body. In many instances crime can rapidly be excluded in favor of accidents, suicides or even natural causes. This is most useful and cost effective function as a spurious murder investigation involving expensive public facilities like police force, vehicles in investigation process.

Photos are necessary for instant recording of scene of crime. It is also required to draw a simple sketch or Diagram of the Position of the body with location of blood stains, which gives much information. Measure the distances between body and the surrounding article or objects.

\section{Review works}

Crime scene investigation is based on scientific reasoning. The investigation of the crime scene is systematic, methodical and logical. It started with the initial response to a crime scene and continues through the scene security, the crime scene documentation, the recognition of physical evidence, the enhancement of patterns, the physical evidence collection, packaging and preservation, the physical evidence examination, the crime scene analysis and profile, and ultimately concludes at the crime scene reconstruction. It is also important to see footprints at the crime scene and it can help to find out male or female who may be involved in the crime. Fabric type, weave of the fabric, position and volume of blood dropped influence the stain pattern formed. For each fabric type, fabrics of four shades in particular are obtained. They are - white, gray, maroon, black.

The latent footprint is not visible to bare eye. If a person walks on a floor and his/her foot are dry then footprint impression is known as latent print. In case of visible footprint or patent print, wet soles of feet on a dry floor will produce it. It is visible to the bare eye and effective for investigation purpose. In case of impressed prints foot impressions are left on soft, pliable or particularly impressionable surface such as clay surface, molten wax surface and the like. These impressions are visible to the naked eye and can be viewed or photographed without development [1].

Footprint is an important mark in crime investigation. Several studies have shown that dimension of foot and footprint is a very good indicator of stature and gender of a person. Correlation coefficient and regression analysis are very important part of those studies. Researcher studied footprints from adult males from a section in India. The age group of the male subjects ranged from 18 to 30 years. The highest positive correlation coefficient was recorded for toe length measurements (0.82-0.87) [2].

Gender identification/prediction with $95.6 \%$ accuracy was recorded for right foot measurements and $96.4 \%$ accuracy was recorded for left foot measurements by Zeybek, et al. About 249

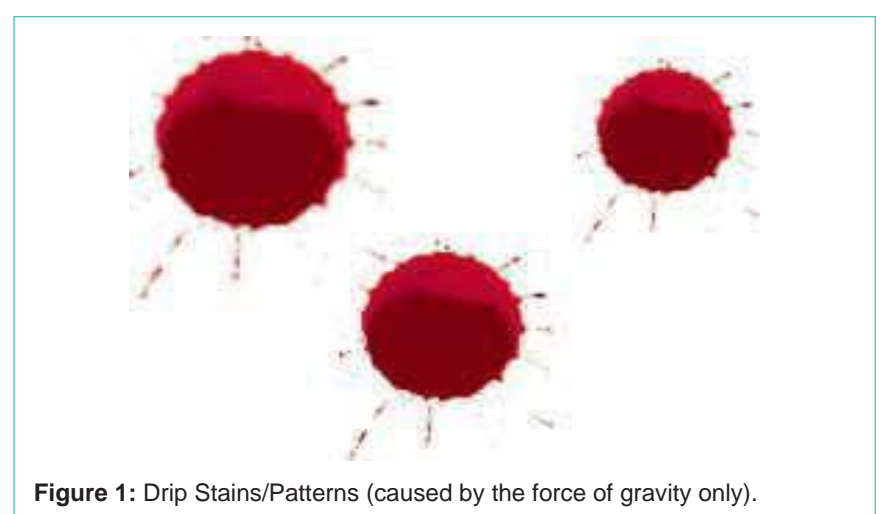




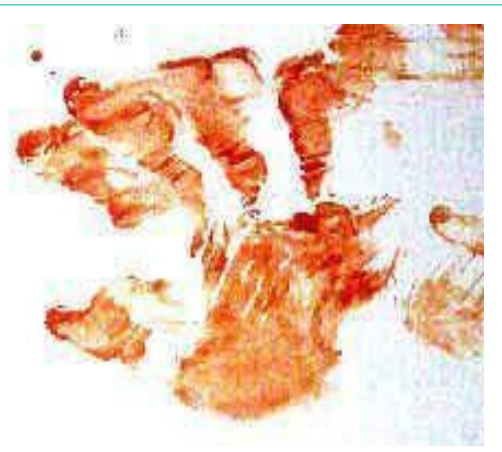

Figure 2: Transfer stain/patterns in fabrics.

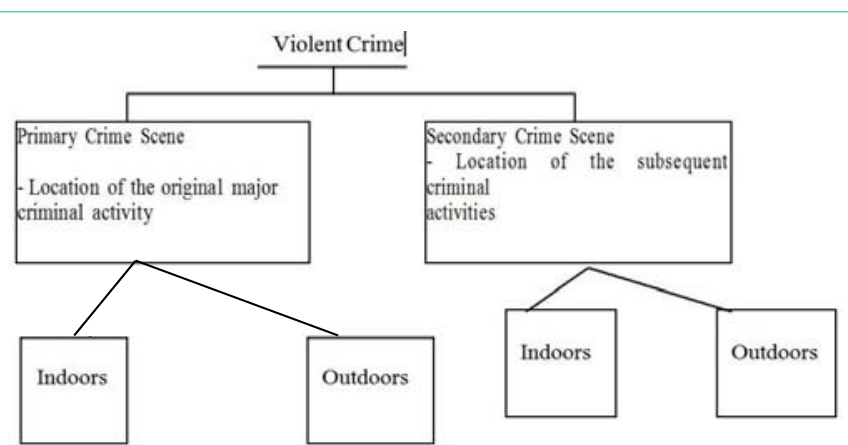

Figure 3: Graphical representation of crime scene classification.

students who were attending Medical Faculty of Dokuz Eylul University and School of Physical Therapy and Rehabilitation in Turkey took part in the study [3].

Bloodstains are of three basic types: passive stains, transfer stains and projected or impact stains. Passive stains include drops, flows and pools, and typically result from gravity acting on an injured body. Figure 1 and Figure 2 show strain patterns to be looked in the crime scene.

Jaydip Sen and Shila Ghosh studied foot length and foot breadth of adult residing in different villages located in the Darjeeling district of West Bengal. The study reported 92\% prediction accuracy [4].

BPA provides information not only about what happened, but just as importantly, what could not have happened. This information helps the investigator in reconstructing the crime, corroborating statements from witnesses, and including or excluding potential perpetrators from the investigation. The fabrics can be particularly divided into 3 basic types [4-7].

Slemko in his work particularly looked at the effect of droplet velocity and fabric composition on bloodstain patterns [8].

Myers and La Free compared data on forcible sexual offenses to both property offenses and other violent crimes. Their findings demonstrate differences in characteristics of the victims, defendants, and evidence of the various crimes but the differences did not change the way officials reacted to the complaints [9]. Krahe in her analysis of police officers and rape, find that officials are skeptical of rape victims. In support of the feminist-conflict theory, their skepticism is amplified if the crime happens in either the suspects' or victims' home [10].

\section{Description of common crime types}

Crime analysis describes a profession and process in which a set of quantitative and qualitative techniques are used to analyze data valuable to police agencies. Crimes are a common social problem affecting the quality of life and the economic growth of a society [9]. It is considered an essential factor that determines whether or not people move to a new city and what places should be avoided when they travel [10]. With the increase of crimes, law enforcement agencies are continuing to demand advanced geographic information systems and new data mining approaches to improve crime analytics and better protect their communities (Figure 3) shows the type of crimes normally held and denoted as crime types.

Sex is understood as the biological difference between men and women. Rape is a highly gendered violent behavior whereas the majority of the sexually violent perpetrators are men and the majority of their victims are women. Rape, the most common form of violence against women has been a part of human culture and is a profound violation of woman's bodily integrity and can be a form of torture.

\section{Case Presentation}

Crime scene investigation is related to science, logic and law. Processing a crime scene is a long, tedious process that involves purposeful documentation of the conditions at the scene and the collection of any physical evidence that could possibly illuminate what happened and point to who did it. There is no typical crime scene where there is no typical body of evidence and there is no known investigative approach.

A fifty-year man on 24.04.2015 lodged a written complain to the police station he received a phone call from his neighbor that nobody open the door of his house. The neighbor requested him to come to his house. At around $17.45 \mathrm{hrs}$ he reached his house and found his wife was lying dead at ground floor with multiple injury marks in the body and pool of blood was lying in the room. He suspected unknown person murdered her wife. On the basis of his complain police lodged a case for investigation. After investigation based on FIR police initially thought that it is a case of rape. The police authority filed the case and visited the spot along with photographer and medical expert.

The body was sent to postmortem examination. Two things that are must and which the doctor has to ensure during postmortem are:

1. Identify of the body is important as and when body is placed before doctor.

2. If relations are available, identification is also to be obtained from relations.

The opinion of Autopsy Surgeon was that death was due to the effect of manual strangulation of neck, ante mortem and homicide in nature. The other injury in the body of the victim was due to the result of physically and sexual assault. The details of seizure list included the following items from the crime spot:

1. One Samsung Mobile and one extra Sim.

2. One bottle with some liquid inside it.

3. Two packets of Sindur.

4. One used condom and two unused condoms. 


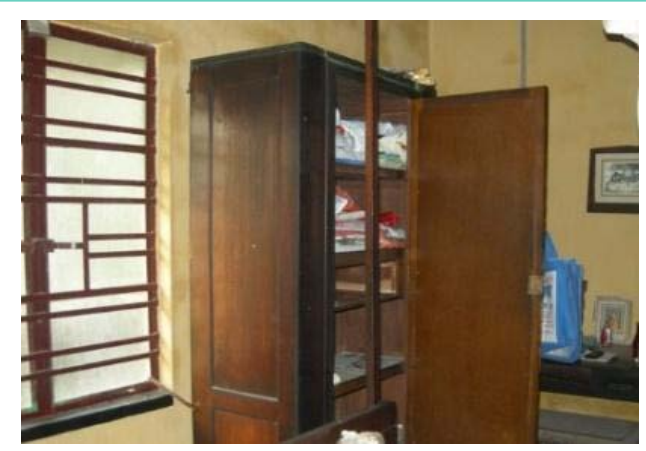

Figure 4: Inside the room.

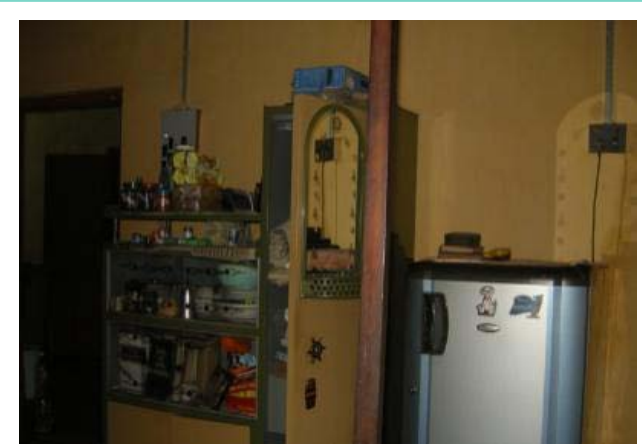

Figure 5: Other side of the Room.

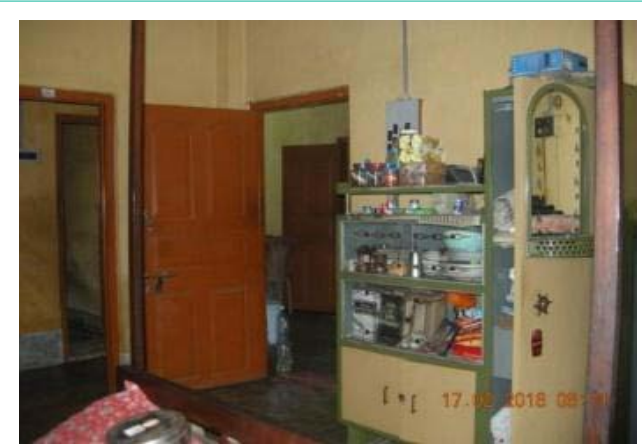

Figure 6: Front Side of the Room.

5. One black colour hair band

6. One towel with blood stain

7. One Bill on which one name indicating that he purchased mobile phone.

8. Two spoons with blood stain.

9. Two sandals of white and pink colour of number 7 in size.

10. Bed sheet containing blood was also found

Police talked to the neighbor and found that the name on the bill had been visiting the house quite often. The owner of the shop confirmed that the person purchased paint and other hardware equipment from him and he issued the bill which was found from the room. Finger print expert took fingerprint from the accused. The husband informed the police that her wife was beautiful and both of them were happy family. He stated that some miscreants killed her

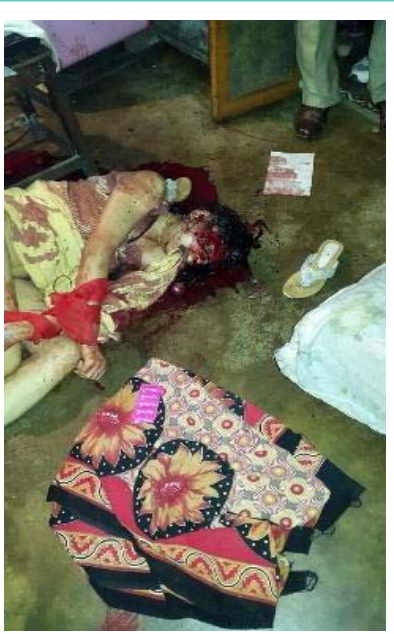

Figure 7: Dead Body of Victim.

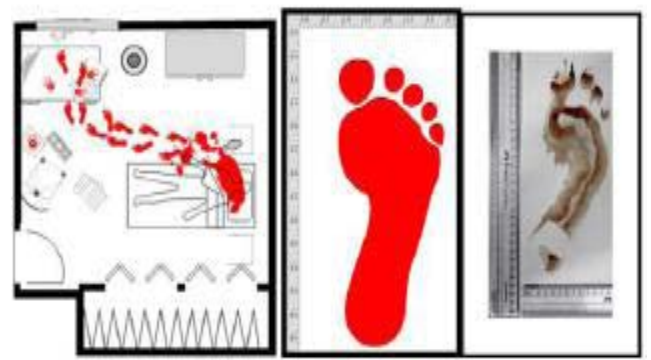

Figure 8: Foot Prints were Present in the Room.

wife and some costly important things were missing from the room. After few days police arrested the person for interrogation. After interrogation police arrested a number of persons and took them in their custody. After interrogating other persons police authority did not convinced about their offences and discharged them with some conditions. An enlarged view of the room at the crime scene in which the dead bodies of victims and foot prints were present. The following photos were taken from the spot. These are shown in Figure 4 to Figure 8.

\section{Case analysis}

From the seizure list and also from the description from the neighbor, it revealed that the detent person played a vital role in the crime. The neighbor saw that the person entered into the house at about 1 p.m. with two soft drinks bottles and later he came out from the house with blood stain in his shirt.

BPA interprets the shape and distribution of bloodstains in the crime spot. In this case two types of strains are available in the wall and room near to victim. First Transfer Patterns are present near the head of the victim. Next Spatter Patterns are observed in the wall and different parts of the room. Strangling is compression of the neck that may lead to unconsciousness or death. In the present case strangulation indication confirmed that she was murder after something happen with her. It is also observed that the constricting force is externally created by no other than murders. It is also found that strangulation in the case is a form of violent asphyxia death when 
the constriction of the air passage at the neck is caused by means of pressure of human fingers, palms or hands upon the throat. Evidence was also found of head injury of the victim.

Here BPA considered three major components: the physical evidence, the informational pieces and the behavioral aspects. Also, consider what happened before, during and after the incident.

BPA collected the following information from the Investigating officer:

A. View of witnesses regarding the incidence, if any.

B. Visualize and note the physical evidence obtained from the crime spot or nearby.

C. Formulate hypotheses about the events that occurred.

E. Determine whether the witness statements are consistent with the physical evidence.

Based on the information collected from the Officer BPA considered the salient points related to the crime. These are:

- Document was stolen.

- $\quad$ Signs of a struggle

- Document Foot prints present not only in the rooms but also more foot prints were seen from rooms to door in a sequence manner.

- Condition of the eyes and some marks on the neck of victim

- Bloodstain in the cloth

- Expirated spatter blood from mouth and bloodstain patterns on bed.

After carefully observing the salient points, the BPA formulates the following hypotheses:

Hypothesis: Some unknown persons rape her first and then strangulated her.

In this particular case the above figures are now used to correlate the crime with the possibilities proposed by bloodstain pattern analyst in terms of hypothesis. Autopsy reports confirm the hypothesis 1. In the case bloods are ejected from mouth of victim and bloodstain appears on bed sheet as exposed blood. Bloodstains result from exposed blood that has meet external surfaces in the environment because of a bloodshed event.
After going through the details of case and considering seizure list, it is expected that more than were present at the crime spot. They initially assaulted physically the lady and later she was strangulated with towel since towel had blood stain. We acknowledge the police authority for documents and help us with photos at the crime spot.

\section{Conclusion}

Interpretation of the shape and distribution of bloodstains connected with a crime and considering the situation along with statements of neighbors, it is considered a case of rape by two persons. After sexually harassed the lady they used towels for strangulation and it is evident from the mark in the neck of the victim.

\section{References}

1. Presentation by Nabanita Basu (MRes Security Sciences), Comparative study of feature extraction algorithms used for fingerprint identification. 2014.

2. Kewal Krishan. Estimation of stature from footprint and foot outline dimensions in Gujjars of North India. Forensic Sci Int. 2008; 175: 93-101.

3. Zeybek G, Ergur I, Demiroglu Z. Stature and gender estimation using foot measurements. Forensic Sci Int. 2008; 181: 54e1-55e1.

4. Sen J, Ghosh S. Estimation of stature from foot length and foot breadth. Forensic Sci Int. 2008; 181: 55e1-56e1.

5. Slemko JA. Bloodstains on Fabric: The Effects of Droplet Velocity and Fabric Composition. International Association of Bloodstain Pattern Analysts News. 2003.

6. Bogomolov A, Lepri B, Staiano J, Oliver N, Pianesi F, Pentl A, Once Upon a Crime: Towards Crime Prediction from Demographics and Mobile Data. CoRR. 14092983. 2014.

7. Arulanandam R, Savarimuthu B, Purvis M. Extracting Crime Information from Online Newspaper Articles', in Proceedings of the Second Australasian Web Conference. Auckland: New Zealand; 2014.

8. Buczak A, Gifford C. Fuzzy association rule mining for community crime pattern discovery, in ACM SIGKDD Workshop on Intelligence and Security Informatics. Washington DC; 2010.

9. Myers M, La Free G. Sexual Assault and its Prosecution: A Comparison with other Crimes. Journal of Criminal Law and Criminology. 1982.

10. Krahe B. Police Officers' Definitions of Rape: A Prototype Study. Journal of Community and Applied Social Psychology. 1991.
Austin J Forensic Sci Criminol - Volume 4 Issue 3 - 2017 ISSN : 2380-0801 | www.austinpublishing group.com Bandyopadhyay et al. (C) All rights are reserved
Citation: Basu N and Bandyopadhyay SK. A Case Study on Sexually Harass Women in a Crime Spot. Austin J Forensic Sci Criminol. 2017; 4(3): 1066 